\title{
High dose nonsteroidal anti-inflammatory drugs compromise spinal fusion
}

\author{
[De fortes doses d'anti-inflammatoires non stéroïdiens compromettent l'arthrodèse \\ vertébrale]
}

Scott S. Reuben MD, ${ }^{*}$ David Ablett FRCP, $†$ Rachel Kaye $\ddagger$

\begin{abstract}
Purpose: Although nonsteroidal anti-inflammatory drugs (NSAIDs) provide benefit to patients following spinal fusion surgery, their routine administration has remained controversial due to concerns about possible deleterious effects on bone healing. The goal of this retrospective study was to assess the incidence of non-union following the perioperative administration of ketorolac, celecoxib, or rofecoxib.
\end{abstract}

Methods: We retrospectively analyzed the data of 434 patients receiving perioperative ketorolac (20-240 $\mathrm{mg}^{-}$day $\left.{ }^{-1}\right)$, celecoxib

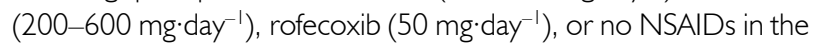
five days following spinal fusion surgery.

Results: There were no significant differences in the incidence of non-union among the groups that received no NSAIDs ( I //I30; $8.5 \%)$, celecoxib 5/60; 8.3\%), or rofecoxib (9/I24; 7.3\%). In contrast, $23 / 120$ of patients (19.2\%) that received ketorolac had a higher incidence $(P<0.00 \mathrm{I})$ of non-union compared to non-NSAID users. However, only 3/50 patients (6\%) receiving low-dose ketorolac $\left(\leq 110 \mathrm{mg} \cdot \mathrm{day}^{-1}\right)$ resulted in non-union which was not significantly different from non-NSAID users. Patients administered higher doses of ketorolac ( $\left.120-240 \mathrm{mg} \cdot \mathrm{day}^{-1}\right)$ resulted in a higher incidence $(P<0.000$ I) of non-union (20/70; 29\%) compared to non-NSAID users. For those patients developing non-union, there was a higher incidence comparing smokers vs non-smokers $(P<0.000$ I $)$ and one level fusion vs two level fusions $(P<0.001)$.

Conclusions: This study revealed that the short-term perioperative administration of celecoxib, rofecoxib, or low-dose ketorolac ( $\leq 110 \mathrm{mg} \cdot \mathrm{day}^{-1}$ ) had no significant deleterious effect on non-

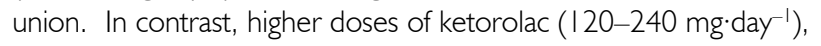
history of smoking, and two level vertebral fusions resulted in a significant increase in the incidence of non-union following spinal fusion surgery.
Objectif : Les anti-inflammatoires non stéroïdiens (AINS) sont bénéfiques après une arthrodèse vertébrale, mais leur administration régulière demeure controversée à cause des effets nuisibles possibles sur la cicatrisation de l'os. Notre étude rétrospective voulait évaluer l'incidence d'absence de fusion à la suite de l'administration périopératoire de kétorolac, célécoxib ou rofécoxib.

Méthode : Nous avons procédé à l'analyse rétrospective de données sur 434 patients qui ont reçu du kétorolac (20-240 mg-jour '), du célécoxib (200-600 mg·jour '), du rofécoxib (50 mg·jour ${ }^{\prime}$ ) ou aucun AINS dans les cinq jours suivant une arthrodèse vertébrale.

Résultats : L'incidence d'absence de fusion osseuse n'était pas significativement différente entre les patients sans AINS (I I/I30; 8,5\%) et ceux qui ont eu du célécoxib 5/60; 8,3\%) ou du rofécoxib (9/1 24; 7,3\%). Par ailleurs, 23/1 20 des patients (19,2\%) qui ont reçu le kétorolac ont présenté une incidence plus élevée $(P<0,001)$ d'absence de fusion en comparaison de ceux qui ont pris des AINS. Seulement 3/50 patients (6\%) recevant de faibles doses de kétorolac

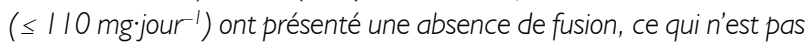
significativement différent des non-utilisateurs d'AINS. Des doses plus élevées de kétorolac ( $120-240$ mg·jour-1 ), comparées aux non-AINS, ont provoqué une plus haute incidence $(P<0,0001)$ d'absence de fusion (20/70; $29 \%)$. L'incidence d'absence de fusion était plus élevée si on compare les fumeurs vs les non-fumeurs $(P<0,000$ l) et la fusion à un niveau vs à deux niveaux $(P<0,001)$.

Conclusion : L'étude a révélé que l'administration périopératoire à court terme de célécoxib, de rofécoxib ou de faibles doses de kétorolac ( $\left.\leq 110 \mathrm{mg} \cdot j o u r^{\prime}\right)$ n'a pas d'effet nuisible significatif sur l'absence de fusion. Par contre, des doses plus élevées de kétorolac (1 20-240 mg.jour ${ }^{\prime}$ ), le tabagisme et des fusions vertébrales à deux niveaux augmentent significativement l'incidence d'absence de fusion à la suite d'une arthrodèse vertébrale.

From the Acute Pain Service, ${ }^{*}$ Baystate Medical Center and the Tufts University School of Medicine, Springfield, Massachusetts, USA; the Department of Anesthesiology, $\dagger$ Calgary Health Region, Calgary, Alberta, Canada; and the Brandeis University, Waltham, Massachusetts, USA. Address correspondence to: Dr. Scott S. Reuben, Baystate Medical Center, 759 Chestnut Street, Springfield, MA 01199, USA. Phone: 413-794-4325; Fax: 413-794-5349; E-mail: scott.reuben@bhs.org Presented in part at the American Society of Regional Anesthesia and Pain Medicine Meeting, Vancouver, British Columbia, Canada, May 2002.

Support was provided solely from institutional and/or departmental source.

Accepted for publication November 3, 2004.

Revision accepted February 14, 2005.

CAN J ANESTH 2005/52: $5 /$ pp 506-512 


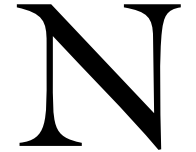

ONSTEROIDAL anti-inflammatory drugs (NSAIDs) inhibit the synthesis of prostaglandins both in the spinal cord and at the periphery, thus diminishing the hyperalgesic state after surgical trauma. ${ }^{1}$ NSAIDs are useful as the sole analgesic after minor surgical procedures $^{2}$ and may have a significant opioid-sparing effect after major surgery. ${ }^{3}$ It is currently recommended that NSAIDs be used in the multimodal analgesic approach for the management of perioperative pain. ${ }^{4,5}$ The recent practice guidelines for acute pain management in the perioperative setting state "unless contraindicated, all patients should receive around-the-clock regimen of NSAIDs, coxibs, or acetaminophen". ${ }^{5}$ Proposed and documented benefits of multimodal therapy include improved pain relief, reduction of the perioperative stress response, reduced opioid-related side effects, shorter hospital stays, decreased hospital costs, increased patient satisfaction, and a reduction in postoperative morbidity and mortality. ${ }^{6,7}$ NSAID administration to patients undergoing spinal fusion surgery has demonstrated significant benefits including improved analgesia (decreased opioid use and pain scores), improvement in postoperative ambulation, shorter hospitalization, and a decreased incidence of nausea, vomiting, and sedation..$^{8-13} \mathrm{~A}$ cost-benefit analysis revealed a net savings to the institution of over \$211,000 per year or over $\$ 350$ per patient in those patients receiving NSAIDs for lumbar spine surgery. ${ }^{12}$ In addition to these short-term analgesic benefits, a reduction in acute pain provided by perioperative NSAID administration may also reduce long-term morbidity following spinal fusion surgery. It is currently believed that there is a continuum of pain after surgery ranging from acute to chronic, and effective treatment of acute pain, may prevent the development of chronic pain syndromes. ${ }^{14,15}$ Further, cyclooxygenase (COX)-2 is thought to play an integral role in the processes of peripheral and central sensitization, and the early intervention with COX-2 inhibitors may thwart the progression of acute pain to chronic pain. ${ }^{16}$

The routine use of COX-2 inhibitors for spinal fusion surgery has remained controversial due to concerns about possible deleterious effects on bone healing. Many investigators recommend that NSAIDs should not be utilized in the multimodal management of acute pain for patients undergoing spinal fusion surgery. ${ }^{17-20}$ Although the data are conflicting, a large body of literature derived from laboratory animal studies suggests that NSAIDs either delay or inhibit bone healing. ${ }^{17-19}$ It is difficult to extrapolate data from animal studies to humans due to the differences in pharmacokinetics between species. Further, in the majority of animal studies cited, ${ }^{17-19}$ NSAID administration occurred over several weeks to months at doses greater than that approved for acute pain and NSAID blood levels were not measured. There are also significant flaws in study methodologies used in the human spinal fusion studies cited. ${ }^{20}$ Numerous uncontrolled patient and surgical factors, marginal power, and retrospective design, all detract from the credibility of these negative findings.

We have been utilizing NSAIDs for almost a decade in the management of acute pain following spinal fusion surgery. ${ }^{9-12}$ The goal of this retrospective study is to examine the effect of NSAIDs on the incidence of non-union at one-year following spinal fusion surgery.

\section{Methods}

The Institutional Review Board approved the retrospective review of hospital charts and databases. The study population was a consecutive sample of 434 patients undergoing elective decompressive posterior lumbar laminectomy with instrumented spinal fusion by a single surgeon within an eight-year period (February 1996-January 2003). Spinal fusion was performed at one or two levels from L4 to sacrum using similar pedicle screw-rod constructs and autologous iliac crest bone graft. Exclusion criteria included more than two level vertebral fusions, patients with a prior history of spinal fusion, undergoing anterior lumbar fusion, or the use of other NSAIDs or glucocorticoids during the study period. Prior to surgery, all patients had standing anteroposterior (AP), lateral, and oblique radiographs of the lumbosacral spine.

Anesthesia was induced with either sodium pentothal or propofol and maintained with either isoflurane or sevoflurane with $70 \% \mathrm{~N}_{2} \mathrm{O}$ in $\mathrm{O}_{2}$. All patients were administered fentanyl $\left(5-10 \mu \mathrm{g} \cdot \mathrm{kg}^{-1} i \mathrm{v}\right)$ or morphine $\left(0.3-0.5 \mathrm{mg} \cdot \mathrm{kg}^{-1} \mathrm{iv}\right)$ intraoperatively. Patients were connected to a patient controlled analgesia pump (Abbott PCA Plus, Abbott Park, Chicago, IL, USA) upon arrival to the postanesthesia care unit which was maintained for the first $24 \mathrm{hr}$ after the completion of surgery. Bed rest was enforced for the first $24 \mathrm{hr}$ postoperatively. Progressive ambulation was then begun through physical therapy. Perioperative NSAID administration included either ketorolac (20-240 $\left.\mathrm{mg} \cdot \mathrm{day}^{-1}\right)$, celecoxib $\left(200-600 \mathrm{mg} \cdot \mathrm{day}^{-1}\right)$, or rofecoxib $\left(50 \mathrm{mg} \cdot\right.$ day $\left.^{-1}\right)$ for five consecutive days according to the anesthesiologist's preference.

Fusion status was determined from the AP, oblique, and flexion-extension radiographs, and either tomography or a computed tomography scan when necessary obtained at one-year follow-up. For a fusion to be 
termed solid, strict criteria were utilized according to previous published studies. ${ }^{21-23}$ The AP radiograph had to show bridging bone bilaterally between transverse processes with trabeculation that was confluent across the fusion mass. Oblique radiographs had to confirm the presence of fusion bone in a confluent pattern between transverse processes. Flexion-extension films were considered to show solid fusion with < $2^{\circ}$ motion on the lateral film. Criteria used to diagnose non-union included evidence of radiolucency around the hardware, collapse of graft height with a gap between the vertebral end plate and the bone graft, shift in position of the graft, and loss of fixation from hardware loosening or dislodgement. In addition, dynamic AP and lateral radiographs that revealed $4 \mathrm{~mm}$ horizontal motion and $\geq 10^{\circ}$ angular motion on lateral films taken with the patient bending indicated non-union. The fusion status was determined solely by radiographic means by an independent radiologist who was blinded to the analgesic technique.

\section{Statistical analysis}

Demographic data (age, height, and weight) and procedure duration were analyzed with analysis of variance. The effect of ketorolac administration on non-union rate was further divided into two daily dose categories: 20 to $110 \mathrm{mg}$ and 120 to $240 \mathrm{mg}$. The rationale for choosing these two dosing categories was based upon previously published guidelines for the perioperative administration of ketorolac. ${ }^{10,24-26} \mathrm{We}$ believe the drug manufacturers' current dosing guidelines for ketorolac $\left(120 \mathrm{mg} \cdot \mathrm{day}^{-1}\right)^{24}$ are excessive and not consistent with the lower doses recommended in the current literature. ${ }^{10,25,26}$ Difference in fusion rate was assessed with a Chi square test or Fisher's exact test. Multivariate logistic regression was used to explore the relationship between NSAID treatment, smoking status, age, gender, and levels of fusion on the odds of non-union. Two-factor interactions were investigated to identify factors that may have synergistic effects on the odds of non-union. Significance was determined at the $P<0.05$ level. SAS® software, version 8.2; (SAS Institute Inc., Cary, NC, USA) was used to perform the statistical calculations.

\section{Results}

A total of 434 patients receiving either ketorolac ( $n=$ $120)$, rofecoxib $(n=124)$, celecoxib $(n=60)$, or no NSAID $(n=130)$ were included in this retrospective study. There were no significant differences among the groups with respect to age, height, weight, duration of surgery, smoking history, or number of vertebral levels fused (Table I). A total of 48 patients (11\%) developed non-union postoperatively. NSAID treatment, smoking status, and levels of fusion were all significant predictors of non-union when included in the multivariate logistic regression. There were no significant differences in the incidence of non-union among the groups that received no NSAIDs, celecoxib, or rofecoxib (Table II). Non-union was identified in 11 of the 130 patients $(8.5 \%)$ who received no NSAIDs, nine of the 124 patients $(7.3 \%)$ who received rofecox$\mathrm{ib}$, and five of the 60 patients $(8.3 \%)$ who received celecoxib (Table II). In contrast, 23 out of 120 patients $(19.2 \%)$ that received ketorolac had a significantly $(P<0.001)$ higher incidence of non-union compared to non-NSAID users. This represents over a threefold greater likelihood of developing non-union with ketorolac administration (Table III). Only three of 50 patients $(6 \%)$ receiving low-dose ketorolac ( $\leq$ $\left.110 \mathrm{mg} \cdot \mathrm{day}^{-1}\right)$ resulted in non-union which was not significantly different from non-NSAID users. Patients receiving higher doses of ketorolac (120-240 mg. day $\left.^{-1}\right)$ had a significantly $(P<0.0001)$ higher incidence of non-union (20 out of 70 patients; $29 \%$ ) compared to non-NSAID users. This represents over an eightfold greater likelihood of developing non-union compared to non-NSAID users (Table III). For those patients developing non-union, there was a significantly higher incidence between smokers and nonsmokers $(P<0.0001)$ and one level fusion vs two level fusions $(P<0.001)$; (Table III). Multivariate logistic regression indicated that the effects of smoking and levels of fusion were greater than additive (i.e., significant smoking status by level of fusion interaction). The effect of smoking on non-union was much greater in patients undergoing two-level fusions relative to those undergoing one-level fusion. Also, the increase in the odds of non-union in patients undergoing two-level fusions relative to those undergoing one-level fusion was larger in smokers.

\section{Discussion}

This study revealed that the short-term perioperative administration of celecoxib, rofecoxib, or low-dose ketorolac $\left(\leq 110 \mathrm{mg} \cdot \mathrm{day}^{-1}\right)$ had no significant deleterious effect on spinal fusion. In contrast, higher doses of ketorolac (120-240 mg.day ${ }^{-1}$ ), history of smoking, and two level vertebral fusions resulted in a significant increase in the non-union rate following spinal fusion surgery.

Although NSAIDs have proven to be beneficial in the multimodal management of pain following spinal fusion surgery, ${ }^{8-13}$ many physicians refrain from the use of these drugs because of a possible deleterious effect on osteogenesis and spinal fusion. ${ }^{17-20}$ Spinal 
TABLE I Patient demographics and surgical data

\begin{tabular}{|c|c|c|c|c|}
\hline & No NSAID & Rofecoxib & Celecoxib & Ketorolac \\
\hline Number & 130 & 124 & 60 & 120 \\
\hline Gender $[\mathrm{M} / \mathrm{F}(\% \mathrm{M})]$ & $77 / 53(59 \%)$ & $72 / 52(58 \%)$ & $36 / 24(60 \%)$ & $69 / 51(58 \%)$ \\
\hline Age $(\mathrm{yr})$ & $44 \pm 13$ & $47 \pm 16$ & $49 \pm 15$ & $46 \pm 19$ \\
\hline Weight $(\mathrm{kg})$ & $79 \pm 15$ & $81 \pm 16$ & $83 \pm 19$ & $80 \pm 12$ \\
\hline Height $(\mathrm{cm})$ & $168 \pm 12$ & $171 \pm 14$ & $169 \pm 11$ & $170 \pm 10$ \\
\hline Duration of surgery (min) & $179 \pm 28$ & $184 \pm 32$ & $171 \pm 29$ & $176 \pm 37$ \\
\hline \multicolumn{5}{|l|}{ Spinal levels fused } \\
\hline 1 level & $91(70 \%)$ & $85(69 \%)$ & $45(75 \%)$ & $84(70 \%)$ \\
\hline 2 levels & $39(30 \%)$ & $39(31 \%)$ & $15(25 \%)$ & $36(30 \%)$ \\
\hline Smokers & $39(30 \%)$ & $35(29 \%)$ & $17(28 \%)$ & $33(28 \%)$ \\
\hline Non-smokers & $91(70 \%)$ & $89(71 \%)$ & $43(72 \%)$ & $87(72 \%)$ \\
\hline
\end{tabular}

Data are presented as mean \pm SD or number $(\%)$. NSAID $=$ nonsteroidal anti-inflammatory drugs. There were no statistical differences between the two groups.

TABLE II Non-union by subgroups

\begin{tabular}{|c|c|c|c|c|c|c|c|}
\hline & No NSAID & Rofecoxib & Celecoxib & Ketorolac & $\begin{array}{l}\text { Ketorolac } \\
\left(20-110 \mathrm{mg} \cdot \mathrm{day}^{-1}\right)\end{array}$ & $\begin{array}{l}\text { Ketorolac } \\
\left(120-240 \mathrm{mg} \cdot \mathrm{day}^{-1}\right)\end{array}$ & Total \\
\hline Number & 130 & 124 & 60 & 120 & 50 & 70 & 434 \\
\hline Non-union & 11 & 9 & 5 & 23 & 3 & 20 & 48 \\
\hline \multicolumn{8}{|c|}{ Spinal levels fused } \\
\hline 1 level & $3 / 91$ & $3 / 85$ & $1 / 45$ & $4 / 84$ & $1 / 35$ & $3 / 49$ & $11 / 305$ \\
\hline 2 levels & $8 / 39$ & $6 / 39$ & $4 / 15$ & $19 / 36$ & $2 / 15$ & $17 / 21$ & $37 / 129$ \\
\hline Smokers & $9 / 39$ & $7 / 35$ & $4 / 17$ & $20 / 33$ & $3 / 10$ & $17 / 23$ & $40 / 124$ \\
\hline Non-smokers & $2 / 91$ & $2 / 89$ & $1 / 43$ & $3 / 87$ & $0 / 40$ & $3 / 47$ & $8 / 310$ \\
\hline Male & $7 / 77$ & $6 / 72$ & $3 / 36$ & $13 / 69$ & $2 / 28$ & $11 / 41$ & $29 / 254$ \\
\hline Female & $4 / 53$ & $3 / 52$ & $2 / 24$ & $10 / 51$ & $1 / 22$ & $9 / 29$ & $19 / 180$ \\
\hline
\end{tabular}

NSAID $=$ nonsteroidal anti-inflammatory drugs.

fusion is a complex process that is influenced by multiple physiologic and mechanical factors. These include patient age, cigarette smoking, surgical technique, number of vertebral levels fused, spinal instrumentation, bone graft composition, use of recombinant bone morphogenetic protein, and electrical stimulation. ${ }^{17-19}$ In particular, the use of NSAIDs has received considerable attention with regard to its effect on spinal fusion. Unfortunately, there are currently only two studies in humans which have examined the effect of NSAIDs on spinal fusion..$^{21,27}$ In a retrospective study of 83 patients undergoing posterolateral fusion for isthmic spondylolisthesis, single-level fusions showed an overall union rate of $82 \%$, and two-level fusions, a $74 \%$ rate. ${ }^{21}$. However, patients who continued to take NSAIDs for more than three months postoperatively showed significantly lower union and success rates $(44 \%$ and $37 \%)$. In a retrospective study of 288 patients undergoing spinal fusion surgery, Glassman et al. ${ }^{27}$ demonstrated that non-union was five times more likely to occur if ketorolac, a parenteral NSAID, was administered postoperatively compared with no NSAID use. A total of 121 patients received no NSAID after surgery, whereas 167 patients received ketorolac. There were five (4\%) non-unions in the group receiving no NSAIDs and 29 (17\%) non-unions in the ketorolac group $(P<0.001)$. There was a dose-dependent relationship between non-union rate and ketorolac use up to the range of nine to 12 doses per patient. The results of this study led Glassman et al. ${ }^{27}$ to recommend that NSAIDs be avoided in the early postoperative period following spinal fusion surgery.

However, we believe the NSAID administration in these two studies ${ }^{21,27}$ does not correlate with acceptable clinical practice for acute pain management. NSAIDs were administered either for a prolonged period of time ( $\geq$ three months $)^{21}$ or using excessive doses $\left(>2 \mathrm{mg} \cdot \mathrm{kg}^{-1} \cdot \mathrm{day}^{-1}\right)$ of ketorolac. ${ }^{27}$ We believe that prolonged and/or high dose NSAID administration may be deleterious to spinal fusion and thus limit the use of these drugs to the lowest effective dose for 
TABLE III Multivariate odds ratio, 95\% confidence intervals for non-union

\begin{tabular}{|c|c|c|}
\hline Group comparison & Odds ratio, 95\% confidence interval & P Value \\
\hline Rofecoxib vs no NSAID & $1.2(0.4-3.9)$ & NS \\
\hline Celecoxib vs no NSAID & $1.0(0.2-3.7)$ & NS \\
\hline Ketorolac ps no NSAID & $3.3(1.0-10.3)$ & $<0.001$ \\
\hline Ketorolac $\left(\leq 110 \mathrm{mg} \cdot\right.$ day $\left.^{-1}\right)$ vs no NSAID & $1.2(0.2-6.1)$ & NS \\
\hline Ketorolac $\left(120-240{\left.\mathrm{mg} \cdot \text { day }^{-1}\right)}^{-1}\right.$ vs no NSAID & $8.8(2.8-28.0)$ & $<0.0001$ \\
\hline Smokers vs no smokers & $14.7(5.3-40.9)$ & $<0.0001$ \\
\hline 1 level fusion & $4.1(1.1-14.7)$ & \\
\hline 2 level fusion & $53.1(11.1-254.5)$ & \\
\hline 2 level fusion vs 1 level fusion & $5.6(2.0-15.5)$ & $<0.001$ \\
\hline Nonsmokers & $1.5(0.3-8.2)$ & \\
\hline Smokers & $20.1(6.4-63.1)$ & \\
\hline
\end{tabular}

NS = not significant. NSAID = nonsteroidal anti-inflammatory drugs. Odds ratio were computed from a multivariate logistic regression model including NSAID treatment, smoking status, levels of fusion, and the interaction between smoking status and levels of fusion.

less than one week. In the retrospective study by Glassman et al. ${ }^{27}$ ketorolac was administered in doses greater than $2 \mathrm{mg} \cdot \mathrm{kg}^{-1} \cdot \mathrm{day}^{-1}$. The appropriate analgesic dose of ketorolac is controversial. Pre-marketing clinical investigations demonstrated that 30 to $90 \mathrm{mg}$ of ketorolac provided postoperative analgesia similar to 6 to $12 \mathrm{mg}$ of morphine and 50 to $100 \mathrm{mg}$ of meperidine. ${ }^{28-30}$ Since ketorolac has been marketed, there have been reports of death due to gastrointestinal and operative site bleeding. ${ }^{31}$ In a response to these adverse events, the drug's manufacturer recommended reducing the dose of ketorolac from 150 to $120 \mathrm{mg} \cdot \mathrm{day}^{-1} .^{24}$ The European Committee for Proprietary Medicinal Products recommended a further maximal daily dose reduction to $60 \mathrm{mg}$ for the elderly and to $90 \mathrm{mg}$ for the non-elderly. ${ }^{25}$ We have previously shown that ketorolac $7.5 \mathrm{mg}$ administered every six hours $\left(0.4 \mathrm{mg} \cdot \mathrm{kg}^{-1} \cdot \mathrm{day}^{-1}\right)$ is the optimal analgesic dose for spinal fusion surgery. ${ }^{10}$ Glassman et al. ${ }^{27}$ utilized over five times these ketorolac doses in their clinical investigation of spinal fusion surgery. The inhibitory effect of ketorolac on bone repair and fusion was found to be a dose-related phenomenon. ${ }^{18,27,32}$ In a rabbit femoral defect model, ${ }^{18}$ the administration of low-dose ketorolac (1.75 $\mathrm{mg} \cdot \mathrm{kg}^{-1} \cdot \mathrm{day}^{-1}$ ) for one or five weeks postoperatively had no deleterious effect on bone healing. Ho et al. ${ }^{32}$ demonstrated that ketorolac $2 \mathrm{mg} \cdot \mathrm{kg}^{-1}$. day ${ }^{-1}$ for six weeks had minimal effect on bone repair in a rabbit ulnar defect model. In contrast, ketorolac 4 $\mathrm{mg} \cdot \mathrm{kg}^{-1} \cdot \mathrm{day}^{-1}$ significantly decreased the torsional stiffness and energy absorption of the grafted ulnae and decreased the maximum torque in the intact and the grafted bones. In our present study, we also demonstrated a dose-dependent deleterious effect of ketorolac on bone healing. The incidence of non- union was significantly higher for those patients receiving ketorolac 120 to $240 \mathrm{mg} \cdot \mathrm{day}^{-1}$. In contrast, low-dose ketorolac $\left(\leq 110 \mathrm{mg} \cdot \mathrm{day}^{-1}\right)$ resulted in no significant increase in non-union when compared to non-NSAID users.

In contrast to nonspecific NSAIDs, we believe that the use of COX-2 specific inhibitors represents a significant therapeutic advance in the perioperative management of pain for spinal fusion surgery. Although the perioperative administration of nonspecific NSAIDs may provide effective analgesia, their ability to decrease platelet aggregation and increase bleeding time may increase the incidence of perioperative bleeding due to inhibition of thromboxane $\mathrm{A}_{2} \cdot{ }^{2,3,33} \mathrm{In}$ fact, ketorolac is contraindicated as a prophylactic analgesic prior to any major surgery. ${ }^{24}$ In contrast, because COX-2 specific NSAIDs have no inhibitory effect on platelet function, these drugs can be safely administered as preemptive analgesics for a variety of surgical procedures ${ }^{34,35}$ without an increased risk of perioperative bleeding.

Several investigators have examined the effect of selective COX-2 inhibitors on spinal fusion in the animal model. ${ }^{36-39}$ Long et al. ${ }^{36}$ concluded that celecoxib does not significantly inhibit the rate of spinal fusion in the rabbit model and perhaps the inhibitory effects of NSAIDs on bone healing are likely mediated by inhibition of COX-1. However, Simon et al. ${ }^{37}$ later demonstrated that both celecoxib and rofecoxib inhibited fracture healing to varying degrees in the rat model. Recently, it has been suggested that the deleterious effects of COX-2 inhibitors on fracture healing may be reversible with short-term treatment. ${ }^{38,39}$ Gerstenfeld and Einhorn ${ }^{39}$ examined the effects of ketorolac, valdecoxib, or vehicle over a seven- or 21day time course. This study revealed that animals 
treated for seven days had no statistically significant differences in the rate of non-unions after either 21 or 35 days of healing. In contrast, 21 days of treatment led to statistical differences in the rate of non-unions for valdecoxib after 21 days but the differences disappeared by 35 days. The data from this study suggested that both specific COX-2 inhibitors and nonselective NSAIDs delay fracture healing, but the magnitude of the effect was related to the duration of treatment. These authors ${ }^{39}$ concluded that "extrapolation of these findings to a clinical setting suggests that management of fracture-associated pain with inhibitors of COX-2 should neither impair nor delay healing as long as the duration of treatment is consistent with current standards of care".

The results of our present study concur with these investigators' findings. ${ }^{39}$ We observed no significant increase in the incidence of non-union when either celecoxib or rofecoxib was administered for five consecutive days in doses approved for acute pain management. Although low-dose ketorolac had no significant deleterious effect on spinal fusion, because it cannot be safely administered as a preemptive analgesic, we currently use only COX-2 specific inhibitors. We limit the administration of these analgesics for less than one week following spinal fusion surgery. We are in agreement with other investigators, that it is better to stigmatize smoking and not NSAID use in bone surgery. ${ }^{40}$ Our results concur with other investigators $^{21,27}$ that the risk of smoking has a significant deleterious effect on spinal fusion. In the present study, smokers undergoing spinal fusion surgery were over 14 times more likely to develop non-union compared to non-smokers. Further, $74 \%$ of patients who were smokers and administered high-dose ketorolac developed non-union postoperatively.

In conclusion, this study revealed that the shortterm perioperative administration of celecoxib, rofecoxib, or low-dose ketorolac $\left(\leq 110 \mathrm{mg} \cdot\right.$ day $\left.^{-1}\right)$ had no significant deleterious effect on non-union. In contrast, higher doses of ketorolac (120-240 mg.day ${ }^{-1}$, history of smoking, and two level vertebral fusions resulted in a significant increase in the incidence of non-union following spinal fusion surgery. We currently recommend the short-term perioperative use of COX-2 specific inhibitors for the management of pain following spinal fusion surgery.

\section{References}

1 McCormack K. Non-steroidal anti-inflammatory drugs and spinal nociceptive processing. Pain 1994; 59: 9-43.

2 Souter AJ, Fredman B, White PF. Controversies in the perioperative use of nonsteroidal antiinflammatory drugs. Anesth Analg 1994; 79: 1178-90.

$3 \mathrm{Dahl} \mathrm{JB}$, Kehlet $H$. Non-steroidal anti-inflammatory drugs: rationale for use in severe postoperative pain. $\mathrm{Br}$ J Anaesth 1991; 66: 703-12.

4 U.S. Department of Health and Human Services. Acute Pain Management Guideline Panel. Acute pain management: operative or medical procedures and trauma. Clinical practice guideline. AHCPR Pub. No. 92-0032. Rockville, MD: Agency for Health Care Policy and Research, Public Health Service, 1992; Feb: 15-26.

5 Ashburn MA, Caplan RA, Carr DB, et al. Practice guidelines for acute pain management in the perioperative setting. An updated report by the American Society of Anesthesiologists Task Force on acute pain management. Anesthesiology 2004; 100: 1573-81.

6 Keblet H, Dabl JB. The value of "multimodal" or "balanced analgesia" in postoperative pain treatment. Anesth Analg 1993; 77: 1048-6.

7 Kehlet H, Wilmore DW. Multimodal strategies to improve surgical outcome. Am J Surg 2002; 183: 630-41.

8 Kinsella J, Moffat AC, Patrick JA, Prentice JW, McArdle CS, Kenny GN. Ketorolac trometamol for postoperative analgesia after orthopaedic surgery. Br J Anaesth 1992; 69: 19-22.

9 Reuben SS, Connelly NR, Steinberg R. Ketorolac as an adjunct to patient-controlled morphine in postoperative spine surgery patients. Reg Anesth 1997; 22: 343-6.

10 Reuben SS, Connelly NR, Lurie S, Klatt M, Gibson CS. Dose-response of ketorolac as an adjunct to patientcontrolled analgesia morphine in patients after spinal fusion surgery. Anesth Analg 1998; 87: 98-102.

11 Reuben SS, Connelly NR. Postoperative analgesic effects of celecoxib or rofecoxib after spinal fusion surgery. Anesth Analg 2000; 91: 1221-5.

12 Reuben S, Ekman EF. The effect of cycolo-oxygenase-2 inhibition on analgesia and spinal fusion. J Bone Joint Surg Am 2005; 87: 536-42.

13 Turner DM, Warson JS, Wirt TC, Scalley RD, Cochran $R S$, Miller KJ. The use of ketorolac in lumbar spine surgery: a cost-benefit analysis. J Spinal Disord 1995; 8: 206-12.

14 Cousins MJ, Power I, Smith G. 1996 Labat lecture: pain-a persistent problem. Reg Anesth Pain Med 2000; 25: 6-21.

15 Perkins FM, Keblet $H$. Chronic pain as an outcome of surgery. A review of predictive factors. Anesthesiology 2000; 93: 1123-33.

16 Samad TA, Sapirstein A, Woolf CJ. Prostanoids and pain: unraveling mechanisms and revealing therapeutic targets. Trends Mol Med 2002; 8: 390-6.

17 Gajraj NM. The effect of cyclooxygenase-2 inhibitors 
on bone healing. Reg Anesth Pain Med 2003; 28 : 456-65.

18 Dumont AS, Verma S, Dumont RJ, Hurlbert J. Nonsteroidal anti-inflammatory drugs and bone metabolism in spinal fusion surgery: a pharmacological quandary. J Pharmacol Toxicol Methods 2000; 43: 31-9.

19 Maxy RJ, Glassman SD. The effect of nonsteroidal anti-inflammatory drugs on osteogenesis and spinal fusion. Reg Anesth Pain Med 2001; 26: 156-8.

20 Wedel DJ, Berry D. "He said, she said, NSAIDs". Reg Anesth Pain Med 2003; 28: 372-5.

21 Deguchi M, Rapoff AJ, Zdeblick TA. Posterolateral fusion for isthmic spondylolisthesis in adults: analysis of fusion rate and clinical results. J Spinal Disord 1998; 11: 459-64.

22 Steinmann JC, Herkowitz HN. Pseudarthrosis of the spine. Clin Orthop 1992; 284: 80-90.

23 Lee C, Dorcil J, Radomisli TE. Nonunion of the spine: a review. Clin Orthop 2004; 419: 71-5.

24 Toradol IV/IM (package insert). Nutley, NJ: Roche Laboratories; 1994.

25 Choo V, Lewis $S$. Ketorolac doses reduced. Lancet 1993; 342: 109.

26 Sevarino FB, Sinatra RS, Paige D, Ning T, Brull SJ, Silverman $D G$. The efficacy of intramuscular ketorolac in combination with intravenous PCA morphine for postoperative pain relief. J Clin Anesth 1992; 4: 285-8.

27 Glassman SD, Rose SM, Dimar JR, Puno RM, Campbell $M J$, Johnson JR. The effect of postoperative nonsteroidal anti-inflammatory drug administration on spinal fusion. Spine 1998; 23: 834-8.

28 O'Hara D, Fragen R, Kinzer M, Pemberton D. Ketorolac tromethamine as compared with morphine sulfate for treatment of postoperative pain. Clin Pharmacol Ther 1987; 41: 556-61.

29 Yee JP, Koshiver JE, Allbon C, Brown CR. Comparison of intramuscular ketorolac tromethamine and morphine sulfate for analgesia of pain after major surgery. Pharmacotherapy 1986; 6: 253-61.

30 Folsland B, Skulberg A, Halvorsen P, Helgesen KG. Placebo-controlled comparison of single intramuscular doses of ketorolac tromethamine and pethidine for post-operative analgesia. J Int Med Res 1990; 18: 305-14.

31 Strom BL, Berlin JA, Kinman JL, et al. Parenteral ketorolac and risk of gastrointestinal and operative site bleeding. A postmarketing surveillance study. JAMA 1996; 275: 376-82.

32 Ho ML, Chang JK, Wang GJ. Antiinflammatory drug effects on bone repair and remodeling in rabbits. Clin Orthop 1995; 313: 270-8.
33 Schafer AI. Effects of nonsteroidal anti-inflammatory therapy on platelets. Am J Med 1999; 106: 25S-35S.

34 Gilron I, Milne B, Hong M. Cyclooxygenase-2 inhibitors in postoperative pain management: current evidence and future directions. Anesthesiology 2003; 99: 1198-208.

35 Sinatra $R$. Role of COX-2 inhibitors in the evolution of acute pain management. J Pain Symptom Manage 2002; 24 (1 Suppl.): S18-27.

36 Long J, Lewis S, Kuklo T, Zhu Y, Riew KD. The effect of cyclooxygenase- 2 inhibitors on spinal fusion. J Bone Joint Surg Am 2002; 84: 1763-8.

37 Simon AM, Manigrasso MB, O'Connor JP. Cyclo-oxygenase 2 function is essential for bone fracture healing. J Bone Miner Res 2002; 17: 963-76.

38 Gerstenfeld LC, Thiede M, Seibert K, et al. Differential inhibition of fracture healing by non-selective and cyclooxygenase-2 selective non-steroidal anti-inflammatory drugs. J Orthop Res 2003; 21: 670-5.

39 Gerstenfeld LC, Einhorn TA. COX inhibitors and their effects on bone healing. Expert Opin Drug Saf 2004; 3: 131-6.

40 Lagerkranser $M$. Better to stigmatize smoking and not NSAID in connection with bone surgery! (Swedish). Lakartidningen 2002; 99: 3338-9. 